\title{
ANTICANCER ACTIVITY OF MICROALGAE EXTRACT ON HUMAN CANCER CELL LINE (MG-63)
}

JIMCY JAMES, JIBU THOMAS*

Department of Biotechnology, Algae Biomass Research Laboratory, School of Agriculture and Biosciences, Karunya Institute of Technology and Sciences, Coimbatore, Tamil Nadu, India. Email: jibuthomas.t@gmail.com

Received: 21 July 2018, Revised and Accepted: 08 September 2018

ABSTRACT

Objective: The objective of the present study is to assess the anticancer effect of limnic algae extract of KACC 2 (Karunya Algae Culture Collection) and KACC 23 against MG-63 cell line.

Methods: Bioactive compounds were extracted from the algae culture by Soxhlet extraction method using methanol as solvent, and the extract was checked for its anticancer activity. Polyphenols were estimated using Folin-Ciocalteu reagent method. The constituents of the extract were analyzed using gas chromatography-mass spectrometry (GC-MS).

Results: The results showed that KACC 2 had more phenolic content than KACC 23 . The half maximal inhibitory concentration value for KACC 2 and 23 was found as $0.386 \mu \mathrm{l} / \mathrm{ml}$ and $0.285 \mu \mathrm{l} / \mathrm{ml}$ of extracts necessary for the $50 \%$ of cell death. GC-MS analysis revealed that the compounds with possible therapeutic effects are quercetin, stigmast-4-en-3-one, epoxygedunin, which has got anticancer activity.

Conclusion: These observations point out that the algae extract of KACC 2 and KACC 23 has anticancer property and the phytoconstituents contributed to the anticancer effects.

Keywords: Microalgae, Anticancer, MG-63 cell line, 3-(4,5-Dimethylthiazol-2-yl)-2, 5-diphenyltetrazolium bromide assay, Gas chromatography-mass spectrometry, Polyphenol.

(C) 2019 The Authors. Published by Innovare Academic Sciences Pvt Ltd. This is an open access article under the CC BY license (http://creativecommons. org/licenses/by/4. 0/) DOI: http://dx.doi.org/10.22159/ajpcr.2019.v12i1.28652

\section{INTRODUCTION}

Algae contribute to the countless chemical compounds that they are able to synthesize because of its varied span in an ecosystem. Various antimicrobial compounds have been identified in microalgae as well as macroalgae. Above 18,000 new compounds have been isolated from marine sources; thus far, a majority of them have not yet been characterized [1]. Hence, microalgae signify a unique opportunity to discover new metabolites. It has been discovered that microalgae have bioactive compounds which have promising anticipatory applications about antifungal, anticancerous, and antibacterial activity [2]. Seeing the present standing of commonly used treatment therapies and their limitations to challenge their opposing effects, the application of bioactive compounds derived from algae will prove useful as compared with traditional treatment methods [3]. Some of the plant products used in traditional medicine illustrate a great deal of consideration to suppress cancer. Algae are a varied source of pharmacologically vital natural products which are minimally spotted [4]. As per the findings, researchers discovered that different kinds of algal extract have the capacity to slow down cancer growth both in animal and laboratory research. These qualities make them potential treatment of cancer [5]. Novelty of the study includes the exploration of promising phytomolecules from the fresh water microalgae for its anticancer activity. The present study is focused to assess the anticancer effect of a limnic algal extract of KACC 2 and KACC 23 against MG-63 cell line to establish the anticancer activity.

\section{MATERIALS AND METHODS}

Extraction of compounds

The compounds were extracted by Soxhlet extraction method using methanol as solvent. The crushed material is positioned inside the thimble in the Soxhlet extractor. Succeeding this, the solvent $(250 \mathrm{ml}$ of methanol) is added to a round bottom flask, which is connected to the Soxhlet extractor and condenser. On heating using mantle, the solvent begins to evaporate going through the apparatus to the condenser. The condensate then dribbles into the reservoir. When the level of solvent reaches the siphon, it surges back into the flask. The cycle continues and eight refluxes were taken. The extract was reduced to near dryness in a rotary evaporator under reduced pressure. The dry extract was dissolved in $5 \mathrm{ml}$ dimethyl sulfoxide (DMSO) and was used for total phenol assay and anticancer activity [6].

\section{Cell culture}

MG-63, the human osteosarcoma cancer cell line which was availed from NCCS, Pune, India, was grown in MEM medium to which $10 \%$ FBS was supplemented, $1 \%$ penicillin, and streptomycin. These cells were observed in a maintained humidified air at $37^{\circ} \mathrm{C}$ with $5 \% \mathrm{CO}_{2}$. The cells were detached by trypsinization during subculture when they reached $80 \%$ confluency. Thereafter, cells were utilized for anticancer experiments [7].

\section{Cell viability assay}

For the measurement of cell proliferation or reduction in cell viability due to apoptosis or necrosis 3-(4, 5-dimethylthiazol-2-yl)-2, 5-diphenyltetrazolium bromide (MTT), cell proliferation and viability assay are a safe, sensitive, and in vitro assay [8]. MG-63 cells are cultured and processed in flat-bottomed, 96-well culture plates, and KACC 2 and KACC 23 extracts were added at concentrations 6, 12, 25, 55, and $85 \mu \mathrm{l}$. According to the experimental design and incubation time, the cells are optimized for each cell type and system. The cells are added to the wells which have tetrazolium compound MTT and are incubated. Metabolically, active cells reduce MTT to insoluble purple formazan dye crystals and detergent is added to the wells, which solubilize the crystals so that the absorbance can be read using a spectrophotometer. Samples are read directly in the wells. For absorbance, the optimal wavelength is $570 \mathrm{~nm}$, but any filter that absorbs between 550 and $600 \mathrm{~nm}$ can be used. The data can was analyzed by plotting cell number versus absorbance, permitting quantitation of variations in cell 
proliferation. The rate of tetrazolium reduction is proportional to the rate of cell proliferation [9].

\section{Gas chromatography/mass spectrometry (GC/MS) analysis}

The methanol fraction was analyzed through GC/MS, through Thermo Trace Ultra GC system with Triplus RHS autosampler DSQ II mass selective detector (Thermo Scientific CO.) Composites were isolated on ZB-35 MS capillary column which enclosed 35\% phenyl polysiloxane as immobile state, column length being $30.0 \mathrm{~m}$, internal diameter being $0.25 \mathrm{~mm}$, and film thickness being $0.25 \mu \mathrm{m} .250^{\circ} \mathrm{C}$ was the temperature of the injector [10]. $1.0 \mu \mathrm{L}$ was injected in splitless mode. Helium (He) was utilized as a carrier gas, and the flow rate of the gas was $1.0 \mathrm{~mL} / \mathrm{min}$. The program of the temperature was as follows: Initial temperature $70^{\circ} \mathrm{C}$ which was maintained for $1 \mathrm{~min}$, thereafter ramping at $60^{\circ} \mathrm{C} / \mathrm{min}$ up to $260^{\circ} \mathrm{C}$, and finally maintained at this temperature for $10 \mathrm{~min}$. The MSD transfer line temperature was $280^{\circ} \mathrm{C}$. MSD was functioned in electron ionization mode for mass spectra determination, with the ionization energy of $-70 \mathrm{eV}$, whereas the mass range scan was $50-650 \mathrm{~m} / \mathrm{z}$. The ion source recorded was $220^{\circ} \mathrm{C}$. The components were identified based on the assessments of the acquired mass spectra with those of NIST Ver:: 11 and WILLEY mass spectra library [11].

\section{Determination of total polyphenol content}

Folin-Ciocalteu method was used to determine the total phenol of the extract [12]. $1 \mathrm{ml}$ aliquot of the sample was taken, to which deionized water $(1.5 \mathrm{ml})$ and $1.0 \mathrm{M}$ Folin-Ciocalteu reagent (FCR) $(0.5 \mathrm{ml})$ were added. These contents were mixed completely. $20 \%$ sodium carbonate solution $(1.0 \mathrm{ml})$ added after $1 \mathrm{~min}$, and the mixture was further mixed thoroughly. The controls have all the reaction reagents excluding the sample. The absorbance was measured at $750 \mathrm{~nm}$ and compared to gallic acid equivalent (GAE) after $30 \mathrm{~min}$ of incubation at $37^{\circ} \mathrm{C}$ [13].

\section{RESULTS AND DISCUSSION}

\section{MTT assay}

MTT assay measures the viability and proliferation of the cells and is thus used to determine the cytotoxic activity of various drugs. The viability of cells reduced with increasing concentration. Higher extract concentrations exhibited stronger anticancer activity. The LD-50 value (extracts needed for the $50 \%$ of cell death) for two algal extract (KACC 2 and KACC 23) was found as $0.386 \mu \mathrm{l} / \mathrm{ml}$ and $0.285 \mu \mathrm{l} / \mathrm{ml}$, respectively. Results indicated that algal extract had significant activity against osteosarcoma (MG-63 cell line).

\section{$\%$ Cell viability $=$ Abs $($ Sample $) / \mathrm{Abs}($ control $) * 100$}

The results indicated the anticancerous activity of the extracts. With increasing concentration of the extract, the absorbance value decreased which displayed a concentration-dependent increase in the anticancer property of the extract.

\section{GC-MS analysis}

GC-MS analysis of the algae extracts revealed the relative abundance of various compounds present in the extract. From the relative abundance versus time graph, different peaks were observed.

The compounds were then cross-referred with the data available from PubChem. The compounds were checked for any reported therapeutic activity by referring to data available on biological assays in PubChem (Table 1 and Figs. 1-3).

\section{Total phenol content}

The total polyphenol contents in KACC 2 and KACC 23 algae extract was measured in terms of GAE (Standard curve equation: $y=0.0032 x-0.0947$, $\mathrm{R}^{2}=0.9982$ ) by FCR. On performing polyphenol estimation using FCR, the amount of polyphenol in KACC 2 and KACC 23 was found to be $53 \%$ and $67.7 \%$, respectively The estimation was performed to confirm the presence of polyphenol and to estimate the amount of polyphenol in the extract. Similarly, a number of studies done, thus far, have focused on the biological activities of phenolic compounds which have stated to have anticancerous properties besides it also supports the result [14].

\section{DISCUSSION}

\section{MTT assay}

The assay was performed on osteosarcoma cells (MG-63 cell line). The test was performed to observe the cytotoxicity of the extract. The MTT assay results indicated that the anticancer activity of the extracts (both KACC 2 and KACC 23) increased with increasing concentration of the extract. The similar trend was observed in the cytotoxicity activity of Solanum nigrum extract against HeLa cell line and vero cell line [15]. The increase in absorbance value displayed a concentration-dependent increase in the anticancer properties of the extract as well. Jayasree et al., 2018 [16], also reported a similar study in marine red algae. Subsequent analysis of the graph obtained after plotting absorbance versus concentration showed the viability of the cells to have significantly reduced. Studies carried out by Garai et al., 2018 [17], reported a similar effect. This leads to the speculation that the microalgae extracts possessed anticancer activity.

\section{GC/MS analysis}

A large number of compounds were identified after analyzing the extract through GC-MS. GC-MS profiling of polyphenolic extract was reported by Ignat et al., 2010 [18]. The compounds were checked for any reported therapeutic activity by referring to data available on biological assays in PubChem. Post-reference, a list of compounds was obtained which had therapeutic effects.

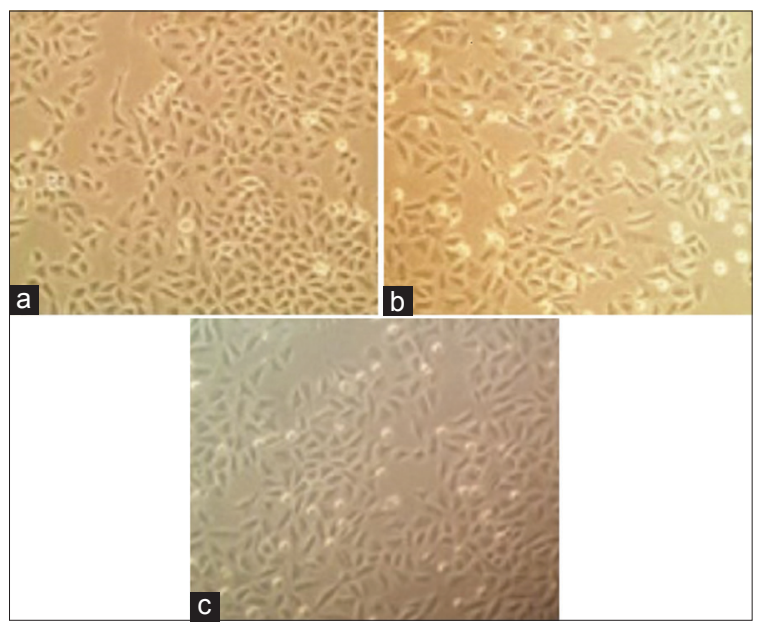

Fig. 1: Treatment of cell line (MG-63) with KACC 2 extract at various concentrations (a) $6 \mu \mathrm{l} / \mathrm{ml}$, (b) $25 \mu \mathrm{l} / \mathrm{ml}$, (c) $55 \mu \mathrm{l} / \mathrm{ml}$

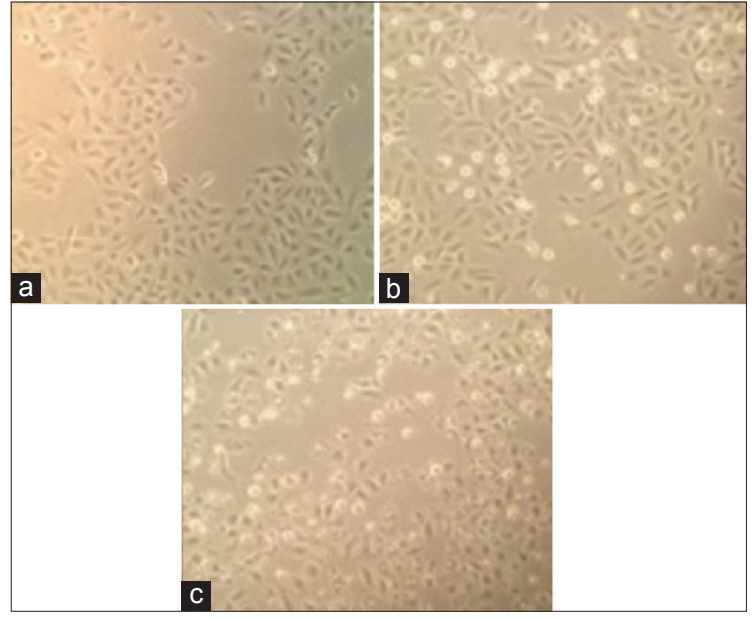

Fig. 2: Treatment of cell line (MG-63) with KACC 23 extract at various concentrations (a) $6 \mu \mathrm{l} / \mathrm{ml}$, (b) $25 \mu \mathrm{l} / \mathrm{ml}$, (c) $55 \mu \mathrm{l} / \mathrm{ml}$ 


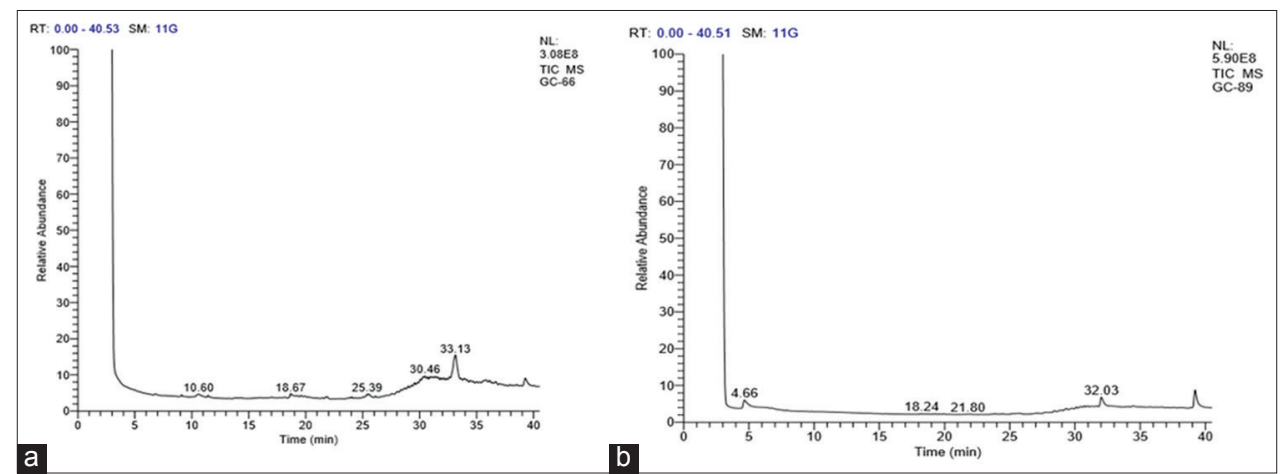

Fig. 3: Gas chromatography-mass spectrometry chromatogram of the methanol extract (a) KACC 2 and (b) KACC 23

Table 1: Therapeutic properties of compounds obtained from the algal extracts identified using GC-MS in KACC 2 and 23

\begin{tabular}{llll}
\hline Retention time & Compound name & Peak area & Possible activities \\
\hline 4.64 & Dimethyl sulfoxide & 15.14 & Anti-inflammatory, antioxidant, and analgesic activities. \\
6.79 & Isochiapin B & 1.03 & Colon anticancer \\
24.43 & Flurandrenolide & 0.6 & Anti-inflammatory and anti-allergic properties \\
27.72 & Quercetin 7,3',' 'trimethoxy & 2.38 & Inhibition of human BCRP expressed in MDCK2 cells \\
28.05 & Quercetin 7,3','-trimethoxy & 1.13 & Inhibition of human BCRP expressed in MDCK2 cells \\
28.67 & Trilinolein & 1.1 & Antioxidant activity, anti-arrhythmic \\
28.99 & Epoxygedunin & 1.03 & Antimalarial, cytotoxic against kb cell line \\
30.46 & Gibberellin A19 methyl ester & 8.7 & Cytotoxic activity \\
30.73 & Epoxygedunin & 6.18 & Antimalarial, cytotoxic against kb cell line \\
33.13 & Stigmast-4-en-3-one (CAS) & 31.49 & Anticarcinogenic and antiatherogenic properties, anti-inflammatory \\
33.13 & Cholest-4-en-3-one & 31.49 & Cytotoxic activity. \\
33.93 & 7-Oxogedunin & 2.62 & Antimalarial, antitumor, antiplasmodial, cytotoxic against rat L6 cells \\
34.46 & Triamcinolone acetonide & 1.22 & cytotoxicity assay \\
36.7 & Astaxanthin & 2.13 & Antiradical anti plasmodial \\
37.02 & Triamcinolone acetonide & 0.93 & Immunosuppressive and anti-inflammatory activity. \\
37.02 & Prednisolone hemisuccinate & 0.93 & Anti-inflammatory activity \\
\hline
\end{tabular}

BCRP: Breast cancer resistance protein, GC-MS: Gas chromatography-mass spectrometry

The compounds such as DMSO, isochiapin B, flurandrenolide, trilinolein, epoxygedunin, and Stigmast-4-en-3-one (CAS) have been reported to possess anticarcinogenic properties in addition to various other therapeutic effects [19]. Cholest-4-en-one has been found to possess cytotoxic activities. The retention time of this compound was $33.13 \mathrm{~s}$, and the extract from which it was obtained was KACC 2. 7-oxogedunin has antimalarial, antitumor, and antiplasmodial activities. It has been reported to possess cytotoxic activity against rat L6 cells [20]. The compound triamcinolone acetonide obtained from KACC 2 extract is reported to have cytotoxic activity. It has a retention time of $34.46 \mathrm{~min}$.

Astaxanthin was found to possess antiradical and antiplasmodial activity [21]. The retention time of the compound was found to be $36.7 \mathrm{~s}$, and it eluted from along with the eluents from KACC 2 extract. Prednisolone hemisuccinate has been known to possess antiinflammatory activity [22]. The retention time was found to be 37.02 , and the extract from KACC 2 was found to possess the compound. 7,3,4- trimethoxy was found to inhibit breast cancer resistance protein in MDCK2 cells [23]. The compound is a polyphenol and was found to be present in both the extracts.

\section{Polyphenol estimation}

Polyphenols are known to possess anticancer activity. The estimation of polyphenol was performed to confirm the presence of polyphenol, as well as, to estimate the amount of polyphenol in the extract. This would, thus, prove the claim that the extract possessed anticancer activity due to the availability of polyphenols. Polyphenol estimation using FCR revealed the amount of polyphenol in KACC 2 and KACC 23 to be $53 \%$ and $67.7 \%$, respectively. This further helped support the claim that the methanolic extracts of the two algae, KACC 2 and 23, possess anticancer activity. Similar reports of polyphenols possessing anticancer activity were reported [24].

\section{CONCLUSION}

The study speculated that the methanolic extracts obtained from the KACC 2 and KACC 23 possessed anticancer activity. The reduced cell viability observed through the MTT assay conducted on osteosarcoma cells (MG-63 cell line) suggested the anticancer activity of the extracts. The contents are rich in polyphenols, and the major phytoconstituents present in the extracts are cholest-4-en-3-one, quercetin, epoxygedunin, and stigmast-4-en-3-one. Thereby concluding that the possibility of anticancer activity is due to the presence of polyphenol present in the extract.

\section{ACKNOWLEDGMENT}

We, the authors would like to thank Karunya Institute of Technology and Sciences, Coimbatore, Tamil Nadu, for giving us the opportunity to do the project. We would like to thank Algae Biomass Laboratory for providing infrastructure and laboratories to work in. Moreover, we also acknowledge all the faculty members and technicians for their assistance.

\section{AUTHORS' CONTRIBUTIONS}

Jimcy James conducted the experiments and collected the data, drafted the article Dr. Jibu Thomas, supervised the experiment, and reviewed the article.

\section{CONFLICTS OF INTEREST}

The authors confirm that there are no conflicts of interest related to this publication.

\section{REFERENCES}

1. Villarreal-Gómez LJ, Soria-Mercado IE, Guerra-Rivas G, Ayala-Sánchez NE. Antibacterial and anticancer activity of seaweeds 
and bacteria associated with their surface. Rev Biol Mar Oceanogr 2010;45:267-75.

2. Prasad MP, Sushant S, Chikkaswamy BK. Phytochemical analysis, antioxidant potential, antibacterial activity and molecular characterization of Clerodendrum species. Int J Mol Biol 2012;3:71-6.

3. Murugesan SU, Bhuvaneswari SU, Sivamurugan VA. Green synthesis, characterization of silver nanoparticles of a marine red alga Spyridia fusiformis and their antibacterial activity. Int J Pharm Pharm Sci 2017;9:192-7.

4. Kumar RV, Murugesan S, Bhuvaneswari S. Phytochemical analysis of red alga Champia parvula (C. Agardh) collected from Mandapam coast of Tamil Nadu, India. Int J Adv Pharm Res 2015;4:15-20.

5. Bayala B, Bassole IH, Scifo R, Gnoula C, Morel L, Lobaccaro JM, et al. Anticancer activity of essential oils and their chemical components-a review. Am J Cancer Res 2014;4:591-607.

6. Kumar KS, Ganesan K, Rao PS. Antioxidant potential of solvent extracts of Kappaphycus alvarezii (Doty) Doty-an edible seaweed. Food Chem 2008;107:289-95.

7. Amruthraj NJ, Raj-Preetam JP, Saravanan S, Lebel-Antoine L. In vitro studies on anticancer activity of capsaicinoids from Capsicum chinense against human hepatocellular carcinoma cells. Int J Pharm Pharm Sci 2014;6:254-558.

8. Ashwini S, Babut S, Saritha MS. Seaweed extracts exhibit anticancer activity against HeLa cell lines. Int J Curr Pharm Res 2016;9:114-7.

9. Varalakshmi B, Anand AV, Karpagam T, Bai JS, Manikandan R. In vitro antimicrobial and anticancer activity of Cinnamomum zeylanicum Linn bark extracts. Int J Pharm Pharm Sci 2014;6:12-8

10. Kavitha J, Palani S. Phytochemical screening, GC-MS analysis and antioxidant activity of marine algae Chlorococcum humicola. World J Pharm Pharm Sci 2016;5:1154-67.

11. Abdel-Aal EI, Haroon AM, Mofeed J. Successive solvent extraction and GC-MS analysis for the evaluation of the phytochemical constituents of the filamentous green alga Spirogyra longata. Egypt J Aquat Res 2015;41:233-46.

12. Zendehbad SH, Mehran MJ, Malla SU. Flavonoids and phenolic content in wheat grass plant (Triticum aestivum). Asian J Pharm Clin Res 2014;7:184-7.
13. Sharma RA, Chandan GO, Chahal AN, Saini RV. Antioxidant and anticancer activity of methanolic extract from Stephania elegans. Int J Pharm Pharm Sci 2017;9:245-9.

14. Yuan YV, Walsh NA. Antioxidant and anti-proliferative activities of extracts from a variety of edible seaweeds. Food Chem Toxicol 2006;44:1144-50.

15. Patel S, Gheewala N, Suthar A, Shah A. In-vitro cytotoxicity activity of Solanum nigrum extract against HeLa cell line and Vero cell line. Int J Pharm Pharm Sci 2009;1:38-46.

16. Jayasree P, Thiruchelvi R, Balashanmugam P. Evaluation of antibacterial, antioxidant, and anticancer potentials from marine red algae Gracilaria corticata. Asian J Pharm Clin Res 2018;11:347-50.

17. Garai S, Ghosh R, Bandopadhyay PP, Mandal NC, Chattopadhyay A. Anti-microbial and anti-cancer properties of echinocystic acid extracted from Luffa cylindrica. J Food Process Technol 2018;9:717.

18. Ignat I, Volf I, Popa VI. A critical review of methods for characterisation of polyphenolic compounds in fruits and vegetables. Food Chem 2011;126:1821-35.

19. Lemieux JM, Wu G, Morgan JA, Kacena MA. DMSO regulates osteoclast development in vitro. In Vitro Cell Dev Biol Anim 2011;47:260-7.

20. Pereira TB, Rocha E Silva LF, Amorim RC, Melo MR, Zacardi de Souza RC, Eberlin MN, et al. In vitro and in vivo anti-malarial activity of limonoids isolated from the residual seed biomass from Carapa guianensis (andiroba) oil production. Malar J 2014;13:317.

21. Dose J, Matsugo S, Yokokawa H, Koshida Y, Okazaki S, Seidel U, et al. Free radical scavenging and cellular antioxidant properties of astaxanthin. Int J Mol Sci 2016;17:103

22. Rosenberg OA, Seiliev AA, Shulga AE, Zhuikov AG, Volchkov VA. Prolongation of anti-inflammatory activity of glucocorticosteroids encapsulated in large oligolamellar liposomes in treatment of arthritis in rabbits. Int J Biomed 2017;7:131-4.

23. Juvale K, Stefan K, Wiese M. Synthesis and biological evaluation of flavones and benzoflavones as inhibitors of BCRP/ABCG2. Eur J Med Chem 2013;67:115-26.

24. Zhang Q, Zhang J, Shen J, Silva A, Dennis DA, Barrow CJ. A simple 96-well microplate method for estimation of total polyphenol content in seaweeds. J Appl Phycol 2006;18:445-50. 